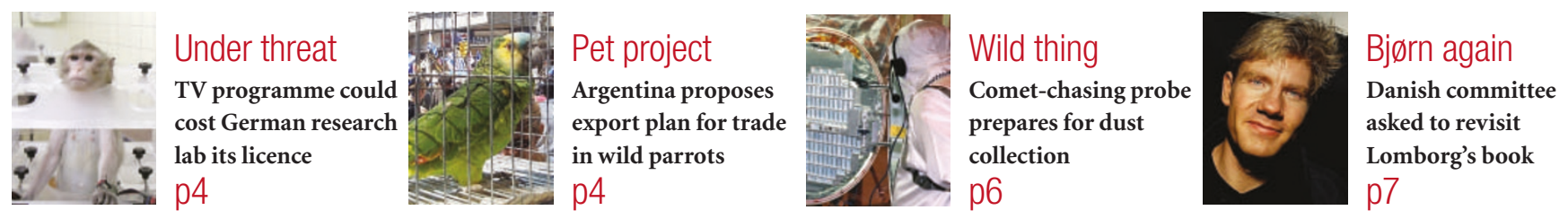

\title{
Plagiarism in Cambridge physics lab prompts calls for guidelines
}

Jim Giles, London

A string of plagiarized papers remains unaltered in the literature, after researchers and journal editors ignored warning signs of the problem, an investigation by Nature has found.

At least eight papers written between 1997 and 2001 by Yung Park, a materials scientist who worked at the University of Cambridge, UK, and the Korea Advanced Institute of Science and Technology (KAIST) in Daejeon, are plagiarized, according to documents examined by Nature. Park has also published at least two pairs of papers with significant overlap in separate journals.

Four of the plagiarized papers have been removed from online journals, or marked as plagiarisms, following investigations into Park's publications by his former colleagues in Korea and by researchers whom he plagiarized. But others remain available either because researchers failed to pass on evidence of plagiarism to journal editors, or because editors were informed and took no action. The status of many of Park's other papers he published about 80 between 1995 and 2002 - has not been fully investigated.

Park came to Cambridge in 1997, where he worked in the lab of materials scientist Kevin Knowles as a visiting scientist under a fellowship from the British Council. Doubts about Park's work were first raised in April 2002 when Bagautdin Bagautdinov, a materials scientist based at the Himeji Institute of Technology in Japan, sent Knowles evidence that Park $^{1}$ had plagiarized one of his papers ${ }^{2}$.

Together with Derek Fray, head of the materials science and metallurgy department at Cambridge, Knowles investigated the allegation. He says that Park tried to show that the work was original, but was unable to provide convincing evidence. As a visiting scientist who was not getting a salary or research funding from Cambridge, Park was asked to leave immediately. He is believed to have returned to Korea, but attempts by
Nature to trace him have failed.

Following Park's departure, other examples of plagiarism in his papers have been identified. For instance, Feodor Borodich, a materials scientist then at the University of Liverpool, spotted three cases and sent details to the editors of the 19 journals that Park had published with while at Cambridge. KAIST researchers investigated papers published by Park under the institute's affiliation and e-mailed six journal editors in June 2002 informing them of one further case of plagiarism and three sets of 'overlapping' papers.

But some other enquiries were not followed up. Knowles spotted three more cases of plagiarism, yet never contacted the editors of the journals involved. One these papers has since been marked online as plagiarized after it was brought to the attention of the journal in question, but the other two remain available ${ }^{3,4}$.

Several journals also failed to act when shown evidence of possible misconduct. The Journal of the American Ceramic Society, for example, which published a paper by Park that shows significant overlap with a previously published paper, says that it received an e-mail from KAIST but only began inves- tigating the matter when contacted by Nature. The Journal of Physics D: Applied Physics, which published a plagiarized paper by Park, confirmed when contacted that it had received the KAIST e-mail but took no action.

Knowles, who was a coauthor on seven of Park's papers that have not come under suspicion, says that in retrospect it was an error for him not to inform editors of the cases of plagiarism that he identified. He says that he is now more aware of misconduct issues, and recently notified journal editors of a pair of duplicate publications not involving Park that he stumbled across.

But the fact that Park was a visiting researcher seems to have influenced Cambridge's approach to the problem. "We hoped it would go away," Fray said when first contacted by Nature. "The person had nothing to do with us. It would have been different if he had been employed by us."

Journal editors who did investigate allegations against Park say that they are disappointed by the responses of other journals. Martin Blume, editor-in-chief at the American Physical Society in Ridge, New York, checked a paper by Park in Physical Review B after being contacted by Borodich. He found no evidence that it was fraudulent. "But when you learn about possible misconduct, you've got to do something," he says.

Editors say that the incident highlights the lack of guidelines for handling plagiarism. The need for a code was discussed last October at a meeting run by the International Union of Pure and Applied Physics in London. Blume, one of the meeting's organizers, says that the union is developing draft guidelines, which should be ready by the autumn.

1. Park, Y. Europhys. Lett. 52, 557 (2000).

2. Bagautdinov, B. Sh. \& Shmyt'ko, I. M. JETP Lett. 59, 182-186 (1994)

3. Park, Y. Solid State Commun. 115, 281-285 (2000) 4. Park, Y. Intl J. Mod. Phys. B 14, 1187-1194 (2000). 